OPEN ACCESS

Edited by:

Renukaradhya J Gourapura, The Ohio State University, United States

Reviewed by: Joan Lunney,

Agricultural Research Service (USDA), United States Tobias Kaeser, North Carolina State University, United States

*Correspondence:

Ivan Díaz

ivan.diaz@irta.es

${ }^{+}$These authors share the last authorship

Specialty section:

This article was submitted to

Comparative Immunology,

a section of the journal

Frontiers in Immunology

Received: 27 August 2021 Accepted: 08 November 2021 Published: 29 November 2021

Citation: Li Y, Mateu E and Díaz I (2021) Impact of Cryopresenvation on Viability, Phenotype, and Functionality of Porcine PBMC.

Front. Immunol. 12:765667. doi: 10.3389/fimmu.2021.765667

\section{Impact of Cryopreservation on Viability, Phenotype, and Functionality of Porcine PBMC}

\author{
Yanli $\mathrm{Li}^{1}$, Enric Mateu ${ }^{1,2,3 \dagger}$ and Ivan Díaz ${ }^{2,3 *+}$ \\ 1 Departament de Sanitat i Anatomia Animals, Universitat Autònoma de Barcelona (UAB), Bellaterra, Spain, ${ }^{2}$ Centre de \\ Recerca en Sanitat Animal, Institut de Recerca en Tecnologies Agroalimentàries (IRTA-CReSA), Bellaterra, Spain, ${ }^{3}$ World \\ Organisation for Animal Health (OIE) Collaborating Centre for the Research and Control of Emerging and Re-Emerging \\ Swine Diseases in Europe (IRTA-CReSA), Bellaterra, Spain
}

The use of frozen peripheral blood mononuclear cells (PBMC) is common in immunological studies. The impact of freezing PBMC has been assessed using human and mice cells, but little information is available regarding domestic animals. In the present study, the phenotype and functionality of frozen porcine PBMC were examined. In a preliminary experiment, three freezing media: fetal bovine serum plus $10 \%$ dimethyl sulfoxide, PSC cryopreservation kit, and Cryostor CS10, were compared regarding the preservation of cell viability and the response of PBMC to mitogens after thawing. After being stored one month in liquid nitrogen, cell viability was above $89 \%$ for all freezing media. The ELISPOT IFN-gamma (IFN- $\gamma$ ) results in response to PHA and of IgG ELISPOT in response to R848+IL-2 were similar to those obtained using fresh PBMC. In the second set of experiments, PBMC were obtained from five pigs vaccinated against Porcine reproductive and respiratory syndrome virus (PRRSV) and then frozen using Cryostor CS10. Recovered cells were phenotyped by flow cytometry using anti-CD3, CD4, CD8, and CD21 antibodies and were used to assess the PRRSV-specific responses in a proliferation experiment, an IFN- $\gamma$ ELISPOT, and an IgG ELISPOT, and compared to the results obtained with fresh cells. The antigen-specific responses of frozen cells were significantly $(p<0.05)$ impaired in the proliferation assay, particularly for CD4/CD8 doublepositive T-cells and for CD21+ cells. Freezing resulted in decreased proliferation when Con A, but not PHA, was used. In ELISPOT, cryopreservation resulted in a decreased frequency of IFN- $\gamma$-secreting cells in response to PRRSV $(p<0.05)$ but the response to PHA was not affected. No differences were observed in the IgG ELISPOT after polyclonal activation. Taken together, cryopreservation of porcine PBMC had a significant impact on the magnitude of recall antigen responses and therefore, it may affect the response of effector/memory cells but seems not to have a major impact on naiive T-cells. These results may help to the better use of frozen porcine PBMC, and to the interpretation of the results obtained from them.

Keywords: PBMC, Elispot, proliferation, porcine, cryopreservation, antigen-specific response 


\section{INTRODUCTION}

Measuring B- and T-cell responses against particular antigens is pivotal to understand how the adaptive immune response develops in the course of an infection, or after vaccination. However, examination of $\mathrm{B}$ and $\mathrm{T}$-cell responses in experimental studies is difficult for several reasons. Under experimental conditions, several groups or batches of animals must be examined considering individual variations. In the case of large animals, implies housing and management in special facilities that have limited allocation capacity. Under farm conditions, although more animals can be examined, the preservation and processing of samples become the main challenge, as farms are usually far from research institutes. Also, it is not always possible to obtain samples, such as lymphocytes from lymph nodes, that can only be collected after killing the animal, due to ethical and economic reasons. Thus, separation of peripheral blood mononuclear cells (PBMC) after bleeding an animal is a common strategy that allows sampling numerous animals at the same time. This is convenient when performing a longitudinal follow-up study (e.g., to evaluate the variation of the adaptive response over time) and elucidating B- and T-cell responses by means of cryopreservation of PBMC. Besides, frozen replicas of PBMC from a given animal can be used to retest or to perform additional tests if necessary.

Cryopreserved PBMC are extensively used in human immunology. However, PBMC, as other cell types, are sensitive to the freezing process. It is well-known that cells can be damaged during freezing, mainly by the intracellular formation of ice crystals -which can mechanically damage the cell-, or by the osmotic imbalance between the intra- and extra-cellular space, resulting in dehydration and shrinkage. In addition, channels formed by the residual unfrozen medium outside the cells could also damage them (1). The impact of cryopreservation on $\mathrm{T}$ and $\mathrm{B}$-cell subsets of PBMC continues to be a controversial issue. For human PBMC, some reports have not observed substantial changes between fresh and frozen cells in terms of phenotype proportions and functionality, such as the antigenspecific responses or the response to mitogens (2-6). Nevertheless, others claimed that cryopreservation alters the proportions of human PBMC subsets $(7,8)$, the antigenspecific IFN- $\gamma$ responses using whole PBMC or specific T-cell subsets $(9,10)$, and impairs the proliferation after mitogen or antigen stimulation as well (3).

In the case of pigs, frozen PBMC are frequently used as well; however, few articles have analyzed the effects of cryopreservation $(11,12)$. Koch et al. (11) indicated that cryopreservation could impair some immunological functions, such as proliferation after PHA-stimulation, while Li et al. (12) found that impact on PBMC stimulated by PMA was disparate, from a significantly lower production of IL-6 in frozen cells to a significantly higher production of IFN- $\gamma$ in frozen PBMC compared to fresh PBMC.

The present study aimed at evaluating the impact of cryopreservation on porcine PBMC in terms of viability, Tand B-cell subset proportions and functionality after mitogen- or antigen-specific stimulation. In a preliminary study, three cryopreservation media were compared to assess the best method to allow the highest survival rate.

\section{MATERIALS AND EQUIPMENT}

\section{Kits}

Porcine IgG ELISPOT ${ }^{\text {BASIC }}$ kit (HRP) including capture antibody MY91/145, biotinylated antibody MT78/145, streptavidin-peroxidase and TMB substrate, $3151-2 \mathrm{H}$, Mabtech, Nacka Strand, Sweden CellTrace ${ }^{\mathrm{TM}}$ Violet Cell Proliferation Kit, C34557, Thermo Fisher Scientific, Waltham, Massachusetts, US

\section{Cell Media}

RPMI Medium 1640 with HEPES wo L-Gln (RPMI-1640), H3BE04-558F, Lonza, Basilea, Switzerland

L-Glutamine $200 \mathrm{mM}, 25030024$, Thermo Fisher Scientific, Waltham, Massachusetts, US

Non-essential amino acids solution (100x), 11140035, Thermo Fisher Scientific, Waltham, Massachusetts, US

Sodium Pyruvate (100 mM), S-8636, Millipore Sigma, Saint Louis, Missouri

2-Mercaptoethanol, M6250-10ML, Merck, Darmstadt, Germany Penicillin-Streptomycin (10,000 U/mL), 15140122, Thermo Fisher Scientific, Waltham, Massachusetts, US

Gentamicin (50 mg/mL), 15750045, Thermo Fisher Scientific, Waltham, Massachusetts, US

Fetal Bovine Serum (FBS), 35-079-CV, Corning, New York, US

Supplemented medium-1 (SM1): RPMI 1640 plus: $1 \mathrm{mM} \mathrm{L-}$ Glutamine, $1 \mathrm{mM}$ non-essential amino acids, $1 \mathrm{mM}$ sodium pyruvate, $5 \mathrm{mM}$ 2-mercaptoethanol, 50,000 IU/l penicillin 1, 50 $\mathrm{mg} / \mathrm{l}$ streptomycin, $50 \mathrm{mg} / \mathrm{l}$ gentamicin and 10\% FBS

Supplemented medium-2 (SM2): RPMI 1640 containing $10 \%$ FBS

\section{Buffers and Others}

Cytiva HyClone ${ }^{\mathrm{TM}}$ Phosphate Buffered Saline (PBS), 10462372, Thermo Fisher Scientific, Waltham, Massachusetts, US

Dulbecco's phosphate-buffered saline (DPBS), 14040133, Thermo Fisher Scientific, Waltham, Massachusetts, US

Horse Serum, New Zealand origin, 16050122, Thermo Fisher Scientific, Waltham, Massachusetts, US

Sodium bicarbonate $\left(\mathrm{NaHCO}_{3}\right), 1.06329$, Merck, Darmstadt, Germany

Sodium carbonate monohydrate $\left(\mathrm{Na}_{2} \mathrm{Co}_{3}\right), 230952-100 \mathrm{gr}$, Merck, Darmstadt, Germany

Bovine Serum Albumin (BSA), A7906-100G, Merck, Darmstadt, Germany

Tween ${ }^{\circledR}$ 20, P1379, Merck, Darmstadt, Germany

Supplemented DPBS (blocking solution for flow cytometry):

DPBS containing 5\% FBS and 5\% horse serum

Carbonate-bicarbonate buffer (sterile): $4.3 \mathrm{~g} \mathrm{NaHCO}_{3}$ and $5.3 \mathrm{~g} \mathrm{Na}_{2} \mathrm{Co}_{3}$ in $1 \mathrm{~L}$ distilled water ( $\mathrm{pH}$ 9.4) 
Standard diluent buffer: $5 \mathrm{~g}$ BSA and $1 \mathrm{~mL}$ Tween-20 in 1L PBS ( $\mathrm{pH} 7.4)$

Wash buffer for ELISPOT: $1 \mathrm{ml}$ Tween 20 in $1 \mathrm{~L}$ distilled water ( $\mathrm{pH} 7.4)$

Wash buffer for flow cytometry: DPBS containing 2\% FBS

Histopaque 1.077, 10771-500ML, Merck, Darmstadt, Germany Trypan blue, T6146, Merck, Darmstadt, Germany

\section{Cryopreservation Products}

Homemade freezing medium: 90\% FBS and 10\% Dimethyl sulfoxide Hybri-Max ${ }^{\mathrm{TM}}$ (DMSO), D2650-100ML, Merck, Darmstadt, Germany

PSC Cryopreservation kit, A2644601, Thermo Fisher Scientific, Waltham, Massachusetts, US

CryoStor $^{\circledR}$ CS10, 07955, Stemcell Technologies, Vancouver, Canada

\section{Mitogens and Others}

Concanavalin A (ConA) from Canavalia ensiformis, C2010, Merck, Darmstadt, Germany

Lectin from Phaseolus vulgaris (red kidney bean) (PHA), L1668-5MG, Merck, Darmstadt, Germany

R848 included in the Porcine IgG ELISPOT ${ }^{\text {BASIC }}$ kit, 31512H, Mabtech, Nacka Strand, Sweden

Recombinant Porcine IL-2 Protein, 652-P2-020/CF, R\&D Systems, Minneapolis, Minnesota, USA

\section{Antibodies, Streptavidin and Substrate Antibodies for IFN- $\gamma$ ELISPOT}

Purified mouse Anti-Pig IFN- $\gamma$ porcine, clone P2G10, 559961, final dilution 1:100, BD Biosciences Pharmingen, San Jose, California, US

Biotin Mouse Anti-Pig IFN- $\gamma$, clone P2C11, 559958, final dilution 1:1000, BD Biosciences Pharmingen, San Jose, California, US

\section{Antibodies for Flow Cytometry}

Mouse anti pig CD3, clone PPT3, MCA5951GA, final dilution 1:200, Bio-Rad, Hercules, California, US

PE Rat Anti-Mouse IgG1, clone A85-1, 562027, final dilution 1:800, BD Biosciences Pharmingen, San Jose, US

FITC mouse anti-pig CD4 $\alpha$, clone 74-12-4, 559585, final dilution 1:100, BD Biosciences Pharmingen, San Jose, US

Alexa Fluor ${ }^{\circledR} 647$ Mouse Anti-Pig CD8 $\alpha$, clone 76-2-11, 561475, final dilution 1:100, BD Biosciences Pharmingen, San Jose, US

Mouse Anti-Porcine CD21-PE, clone BB6-11C9.6, 4530-09, final dilution 1:100, SouthernBiotech, Birmingham, Alabama, USA

\section{Streptavidin and Substrate}

Streptavidin HRP (ELISA GD), SNN2004, Thermo Fisher Scientific, Waltham, Massachusetts, US

TMB substrate for ELISpot, 3651-10, Mabtech, Nacka Strand, Sweden

\section{Field Virus and Vaccine}

Porcine reproductive and respiratory syndrome virus (PRRSV) strain 3267 (batch 40) belonged to our PRRSV bank (13), UAB,
Barcelona, Spain. It was produced and titred in porcine alveolar macrophages obtained from three-weeks old PRRSVnegative piglets.

PORCILIS ${ }^{\circledR}$ PRRS, modified live-virus PRRSV vaccine, MSD Animal Health, Madison, New Jersey, Us

\section{Others}

SepMate $^{\text {TM }} 50$ (IVD), 85450, Stemcell Technologies, Saint Égrève, France

Frosty ${ }^{\mathrm{TM}}$ Freezing Container, 5100-0001, Thermo Fisher Scientific, Waltham, Massachusetts, US

96-Well, Cell Culture-Treated, U-Shaped-Bottom Microplate, 3799, Corning, New York, US

MultiScreen-HA filter plate MAHAS4510, MAHAS4510, Merck, Darmstadt, Germany

\section{Software and Equipment}

FCS Express 7, de novo Software, Glendale, California, US

Statsdirect Statistical software 3.3.5, Statsdirect LTD, Birkenhead, United Kigndom

GraphPad Prism 9.1.2, GraphPad Software Inc., San Diego, California, US

MACSQuant Analyzer 10, Miltenyi Biotec, Bergisch Gladbach, Germany

\section{METHODS}

\section{Preliminary Screening of Freezing Media}

Three products/methodologies for freezing porcine PBMC were compared: Homemade freezing medium; PSC Cryopreservation kit, and CryoStor CS10. Fresh and frozen cells were assessed for viability and functionality by means of trypan blue staining and the IFN- $\gamma$ ELISPOT (using PHA as a mitogenic stimulus) and IgG ELISPOT (using a R848+IL-2 cocktail).

Blood samples from eight commercial pigs of six weeks of age were collected in heparin tubes by jugular venipuncture. PBMC were isolated within $4 \mathrm{~h}$ of collection by density-gradient centrifugation with Histopaque 1.077 in SepMate ${ }^{\mathrm{TM}}$ tubes. After two washes with PBS (400 x g, $10 \mathrm{~min}$ ), PBMC of each animal were resuspended in SM1.

Cells collected in conical sterile tubes were stored overnight at $4^{\circ} \mathrm{C}$. Afterwards, PBMC were counted using trypan blue staining and then were adjusted to the desired working concentrations. Half of the PBMC were used as fresh samples for ELISPOT assays, and the other half were frozen to repeat the same assays one month later.

For cryopreservation procedure with homemade freezing medium, PBMC were gently resuspended in $1 \mathrm{~mL}$ of the freezing medium kept on ice and then transferred to cryovials. Cryovials were immediately distributed in controlled-grade freezing devices $\left(-1^{\circ} \mathrm{C} /\right.$ minute $)$ and stored overnight at $-80^{\circ} \mathrm{C}$. The next day, samples were transferred to a liquid nitrogen tank at $-196^{\circ} \mathrm{C}$.

For PSC Cryopreservation kit and CryoStor CS10, PBMC were frozen following the manufacturer's instructions. Thus, 1 $\mathrm{mL}$ of PSC Cryomedium (chilled at $4^{\circ} \mathrm{C}$ ) was added dropwise to 
the PBMC, while gently rocking the tube back and forth, followed by gentle resuspension of the PBMC pellet. Then, samples were transferred to cryovials that were frozen as above. For CryoStor CS10, PBMC were softly resuspended in 1 $\mathrm{mL}$ (chilled at $4^{\circ} \mathrm{C}$ ) and transferred to cryovials. Cryovials were distributed in controlled-grade freezing devices previously refrigerated at $4^{\circ} \mathrm{C}$. Fifteen minutes after storing the cryovials at $-80^{\circ} \mathrm{C}$ they were softly agitated. The next day, they were transferred to a liquid nitrogen tank at $-196^{\circ} \mathrm{C}$. In all cases, the concentration of PBMC was set at 20-25 x 10 $\mathrm{PBMC} /$ cryovial.

One month later, all samples were thawed by immersion in a $37^{\circ} \mathrm{C}$ water bath. Then, PBMC were transferred to a conical sterile tube and diluted 1/10 in SM1. Samples were centrifuged (400 x g, 10 minutes), the supernatant was removed and PBMC were washed one more time under the same conditions. Finally, PBMC were resuspended again in SM1. For PSC Cryopreservation kit, samples were resuspended according to the manufacturer's instructions; in this case, RevitaCell ${ }^{\mathrm{TM}}$ was added to the SM1 (100 $\mu \mathrm{L}$ in $10 \mathrm{~mL}$ of medium). In all cases, cells were allowed to rest overnight at $37^{\circ} \mathrm{C}\left(5 \% \mathrm{CO}_{2}\right)$ with the cap loosened $(14,15)$. The next morning, PBMC were counted as above and adjusted to the desired working concentration.

The viability of fresh and frozen cells was assessed in a Neubauer chamber after trypan blue staining. Recovery rates were calculated for frozen cells as follows: $\left(\mathrm{n}^{\circ}\right.$ viable cells after thawing $/ \mathrm{n}^{\circ}$ viable cells before freezing) x 100 . The functionality of fresh and frozen $\mathrm{T}$ and B-cells was assessed by means of the IFN- $\gamma$ and IgG ELISPOT assays, respectively.

The IFN- $\gamma$ ELISPOT was performed as previously described (16). Briefly, pre-wetted ( $200 \mu \mathrm{L} /$ well PBS, $1 \mathrm{~min}$ ) filter plates were coated with the P2G10 IFN- $\gamma$ monoclonal antibody (diluted in carbonate-bicarbonate buffer at $1 \mu \mathrm{g} / \mathrm{mL} ; 50 \mu \mathrm{L} /$ well) and incubated overnight at $4^{\circ} \mathrm{C}$. Plates were then washed with sterile PBS $(200 \mu \mathrm{L} /$ well $)$ and blocked for $1 \mathrm{~h}$ at $37^{\circ} \mathrm{C}$ with $100 \mu \mathrm{L} /$ well of $\mathrm{SM} 2$. After removal of the blocking solution, $\mathrm{PBMC}$ were dispensed; 50,000 PBMC/well in $100 \mu \mathrm{L}$ volume for PHA-stimulated wells (plus PHA $10 \mu \mathrm{g} / \mathrm{ml}$ in $100 \mu \mathrm{L}$ SM1) or 500,000 PBMC/well in 100 $\mu \mathrm{L}$ volume plus $100 \mu \mathrm{L}$ SM1 for negative control wells. After $20 \mathrm{~h}$ of incubation $\left(37^{\circ} \mathrm{C} ; 5 \% \mathrm{CO}_{2}\right), \mathrm{PBMC}$ were removed by washing plates five times using wash buffer $(200 \mu \mathrm{L} /$ well $)$ allowing wells to soak well for $1 \mathrm{~min}$ in each wash step. Then, biotinylated detection antibody $\mathrm{P} 2 \mathrm{C} 11$ was added at $0.5 \mu \mathrm{g} / \mathrm{mL}$ ( $50 \mu \mathrm{L} /$ well diluted in the standard diluent) and incubated for $1 \mathrm{~h}$ at $37^{\circ} \mathrm{C}$. After that incubation, plates were washed as above and the reaction was revealed by incubation of plates with streptavidin-peroxidase diluted in standard diluent (final concentration $0.5 \mu \mathrm{g} / \mathrm{mL} ; 50 \mu \mathrm{L}$ / well; incubation $1 \mathrm{~h}$ at $37^{\circ} \mathrm{C}$ ), washing plates as above and addition of insoluble TMB (50 $\mu \mathrm{L} /$ well; 20 minutes, in the dark at room temperature). All tests were run in triplicates. A stereomicroscope binocular was used to read the spots. Frequencies of IFN- $\gamma$ secreting cells (SC) were calculated by subtracting the counts of spots in unstimulated cells, from the counts in PHA-stimulated ones. Results were expressed as responding cells $/ 10^{6} \mathrm{PBMC}$.

The IgG ELISPOT was carried out using a commercial kit. PBMC were split into two $1 \mathrm{~mL}$ aliquots in conical sterile polypropylene tubes. One of the aliquots was stimulated for 72 h $\left(37^{\circ} \mathrm{C}, 5 \% \mathrm{CO} 2\right)$ with the polyclonal activator $\mathrm{R} 848$ and recombinant porcine $\mathrm{IL}-2$ at $1 \mu \mathrm{g} / \mathrm{mL}$ and $10 \mathrm{ng} / \mathrm{mL}$, respectively $(16,17)$. The other aliquot was kept as an unstimulated control. Aliquots were cultivated for three days prior to plating into ELISPOT. Then, cells were washed, resuspended in SM1, re-counted and adjusted to 100,000 cells/ well. Plates previously pre-wetted (200 $\mu \mathrm{L} /$ well PBS, $1 \mathrm{~min})$, coated with the MT421 monoclonal antibody and incubated overnight at $4^{\circ} \mathrm{C}$, were washed and blocked. After removal of the blocking solution, PBMC were dispensed. Antibodies and streptavidin concentrations, as well as times of incubation, washing procedures, etc. were carried out following the manufacturer's instructions. Captured IgG was visualized by the addition of the biotinylated antibody followed by the addition of streptavidin-peroxidase and insoluble TMB. All tests were run in triplicates. Frequencies of IgG-SC were calculated by subtracting the counts of spots in unstimulated cells, from the counts in stimulated ones. Results were expressed as responding cells $/ 10^{6} \mathrm{PBMC}$. In all ELISPOT experiments, IgG and IFN- $\gamma$, all reagents were filtered $(0.2 \mu \mathrm{m})$ before use.

\section{Evaluation of the Cryopreservation Impact on PBMC: Phenotyping and Responses to Mitogens and Specific Antigens}

Five 4-week-old piglets (ear tags number 51, 53, 57, 59, 66) were immunized against PRRSV by vaccinating them with a modified live vaccine (PORCILIS PRRS ${ }^{\circledR}, 2 \mathrm{ml}$, intramuscular). Blood samples were collected in heparin tubes one month later. PBMC were obtained by gradient centrifugation as above; half of the PBMC were used as fresh samples for a set of analyses and the other half were frozen to repeat the same analyses after one month of frozen storage. Since results obtained during the preliminary screening pointed out that Cryostor CS10 provided the best results, it was selected as the freezing medium. The viability of fresh and frozen cells was assessed by trypan blue staining in a Neubauer chamber.

\section{Phenotype of T and B-Cells}

For phenotype characterization, fresh or frozen PBMC were initially incubated with supplemented PBS for 20 min on ice. Then, for Tcells labelling was carried out with antibodies against CD3, CD4 $\alpha$, and $\mathrm{CD} 8 \alpha$. Briefly, PBMC were incubated with the primary antibody anti-CD3 followed by an antibody anti-mouse IgG1-PE. In the next step, antibodies anti-CD4 $\alpha$ :FITC and anti-CD8 $\alpha$ :Alexa Fluor 647 were added. B-cells were labelled separately with an antibody anti-CD21conjugated to PE. Between each step, cells were washed twice with washing buffer and centrifuged at $500 \mathrm{x} \mathrm{g}$ for 5 min. All tests were run in triplicates. Samples were acquired on a MACSQuant Analyzer 10. Fluorescence minus one (FMO) controls, matched isotype controls, and background caused by secondary antibodies were used for gating and analysis. The acquired data were analysed using FCS Express 7.

\section{Proliferation of $\mathrm{T}$ and $\mathrm{B}-\mathrm{Cells}$}

For proliferation, fresh or frozen PBMC were labelled with CellTrace Violet at $5 \mu \mathrm{M}$ according to the manufacturer's 
instructions. Then, cells were suspended in SM1 at $2 \times 10^{6}$ cells/ $\mathrm{ml}$ with $100 \mu \mathrm{l} /$ well plated in a 96-well U-bottom plate. Another $100 \mu \mathrm{l}$ of SM1 or SM1 containing PRRSV isolate 3267 (MOI 0.5), PHA or ConA $(10 \mu \mathrm{g} / \mathrm{ml})$ were added as stimuli. After 5 days, cells were harvested and stained with anti-CD3, anti-CD4 $\alpha$, anti$\mathrm{CD} 8 \alpha$ and anti-CD21 antibody as described above. All tests were run in duplicates.

\section{Frequencies of IFN- $\gamma$-Secreting Cells After Recall Antigen or Mitogen Stimulation Using ELISPOT}

IFN- $\gamma$ ELISPOT was done as described above, using both fresh and frozen PBMC. In this section, besides the PHA response, the antigen-specific (PRRSV) IFN- $\boldsymbol{\gamma}$-SC frequencies were also measured. For this purpose, 500,000 cells/well were stimulated with the PRRSV strain 3267 diluted in SM1 at a multiplicity of infection (MOI) of 0.1. PHA-stimulated cultures and PBMC incubated in SM1 were included as positive and negative controls, respectively as described above. Frequencies of PRRSV-specific and PHA-stimulated IFN- $\gamma$-SC were calculated by subtracting the counts of spots in unstimulated cells from the counts in stimulated ones. Results were expressed as responding cells $/ 10^{6}$ PBMC.

\section{IgG ELISPOT}

IgG ELISPOT to measure polyclonal responses were performed as described above.

\section{Statistical Analysis}

Statistics were performed using StatsDirect v2.7.7. MannWhitney U- and Wilcoxon's signed ranks, or Kruskal-Wallis (Dwass-Steel-Chritchlow-Fligner method for multiple comparisons) non-parametric tests were used for comparisons of means between two or more sets of data, respectively.

\section{RESULTS}

\section{Preliminary Product Screening to Freeze Porcine PBMC}

Using PBMC from eight pigs, the average viabilities for homemade freezing medium, PSC Cryopreservation kit, and CryoStor CS10 after thawing were $96 \pm 2.1 \%^{\mathrm{a}}, 89 \pm 3.2 \%^{\mathrm{b}}$, and $97 \pm 1.1 \%^{\mathrm{a}}$, respectively $(p<0.05)$. Regarding recovery rates, no significant differences were observed (Table 1).

For fresh cells, the average frequency of IFN- $\gamma$-SC stimulated by PHA was $706.0 \pm 86.7$ per $10^{6}$ PBMC. After freezing, although the average value dropped to $674.6 \pm 64.9$ for homemade freezing medium (variance percentage compared to fresh PBMC was $-4.0 \%$ : ranging from $-15.4 \%$ to $+6.5 \%$ in individual samples), $634.6 \pm 53.7$ for the PSC Cryopreservation kit (-9.7\%, ranging from $-15.7 \%$ to $-1.7 \% ; \mathrm{p}=0.07)$, and $670.1 \pm 77.0$ for CryoStor $\operatorname{CS} 10(-5.0 \%$, ranging from $-8.1 \%$ to $+1.5 \%)$, the changes were not significant. None of the cryopreservation procedures increased the background IFN- $\gamma$ production (Supplementary Table 1).

In the IgG ELISPOT, the average frequency of IgG secreting cells for fresh PBMC stimulated with the mitogenic cocktail $(\mathrm{R} 848+\mathrm{IL}-2)$ was $490.6 \pm 186.4$ per $10^{6}$ PBMC. After freezing, the average values were $408.0 \pm 158.9$ for homemade freezing medium (variance percentage compared to fresh PBMC was $-16.9 \%$, ranging from $-21 \%$ to $-11.8 \%$ in individual samples), $386.4 \pm 145.0$ for the PSC Cryopreservation kit $(-21.0 \%$, ranging from $-25.7 \%$ to $-14.4 \%$ ), and $419.2 \pm 161.0$ for CryoStor CS10 ( $-14.8 \%$, ranging from $-21.8 \%$ to $-9.4 \%)$. Although means of variance percentage were lower compared to those observed for IFN- $\gamma$, significant differences between fresh and frozen PBMC for IgG were not found (Supplementary Table 1).

Overall, the freezing process had a small impact on cell viability after using any of the three products. The impact on $\mathrm{T}$ cell functionality -measured as the response against PHA- was almost negligible when using homemade freezing medium or CryoStor CS10. For B-cells, no significant differences were observed between fresh and frozen PBMC for any of the freezing products evaluated. Eventually, Cryostor CS10 was used to further examine the cryopreservation impact on $\mathrm{T}$ and $B$ phenotypes and antigen-specific responses.

\section{Evaluation of the Impact of Cryopreservation on PBMC Impact of Cryopreservation on Viability and Recovery Rates}

In the second study, PBMC viability, as assessed by trypan blue staining, was $99.2 \pm 0.8$ in fresh samples, while the average values of frozen PBMC replicas were $94 \%, 92 \%, 93 \%, 97 \%$, and $93 \%$. No replicas of any animal dropped below $88 \%$. Mean of recovery rates was $72.3 \%$.

\section{Impact of Cryopreservation on the Phenotype and Proliferation of T-Cells}

Phenotypically, TCR- $\alpha \beta$ T-cells $\left(\mathrm{CD}^{+}\right)$were roughly subdivided into naïve $\left(\mathrm{CD} 4^{+} \mathrm{CD} 8^{-}\right)$, cytotoxic $\left(\mathrm{CD} 4^{-} \mathrm{CD} 8^{+}\right)$, memory $\left(\mathrm{CD}^{+} \mathrm{CD}^{+}\right) \mathrm{T}$-cells, and a $\mathrm{CD} 4 / \mathrm{CD} 8$ double negative

TABLE 1 | Viability and recovery rate (percentages) for the preliminary screening of the three freezing media assayed $(n=8)$.

\begin{tabular}{|c|c|c|c|}
\hline & Homemade freezing media & PSC Cryopreservation kit & CryoStor CS10 \\
\hline Viability (\%) & $\begin{array}{c}96.0 \pm 2.1^{a} \\
(93.2-99.0)\end{array}$ & $\begin{array}{l}89.0 \pm 3.2^{b} \\
(85.0-95.1)\end{array}$ & $\begin{array}{c}97.0 \pm 1.1^{a} \\
(95.2-98.3)\end{array}$ \\
\hline Recovery rate (\%) & $\begin{array}{c}70.0 \pm 5.5 \\
(61.1-76.9)\end{array}$ & $\begin{array}{c}70.5 \pm 4.7 \\
(62.5-76.3)\end{array}$ & $\begin{array}{c}71.1 \pm 5.1 \\
(61.8-77.3)\end{array}$ \\
\hline
\end{tabular}

a, bS uperscript letters show significant differences $(p<0.05)$.

Means \pm standard deviations (SD) and ranges. 
subset that have not been well defined (18) (gating hierarchy as shown in Figure 1A). In fresh $\mathrm{PBMC}, \mathrm{CD}^{+}$cells ( $\mathrm{T}$ lymphocytes) accounted on average $49.3 \pm 6.1 \%$ (after excluding debris and red blood cells), compared to $56.0 \pm 5.7 \%$ in frozen cells. Within $\mathrm{CD}^{+}$cells, freezing resulted in an equivalent proportion of $\mathrm{CD} 4^{+} \mathrm{CD} 8^{-}$and $\mathrm{CD} 4^{+} \mathrm{CD} 8^{+}$subsets, but an increase $(\mathrm{p}=0.06)$ of $\mathrm{CD} 4^{-} \mathrm{CD} 8^{-}$subset and, accordingly, a decrease $(p=0.06)$ in $\mathrm{CD}^{-} \mathrm{CD}^{+}$subset compared to the counterparts in freshly isolated cells (Figure 1B).

When PBMC were stimulated with PRRSV 3267 (MOI 0.5) for five days, it was shown that the proliferation of $\mathrm{CD}^{+}$cells (gating hierarchy as shown in Figure 1A) was impaired by freezing, decreasing from $12.2 \pm 5.4 \%$ (fresh cells) to $2.2 \pm$ $2.0 \%$ (frozen cells) $(\mathrm{p}<0.05)$ (Figure 1C). The impairment was also marked $(p<0.05)$ for subsets defined by CD4/CD8 within $\mathrm{CD}^{+}$cells (Figure 1C). Thus, freezing caused a clear reduction in the proliferation of $\mathrm{CD} 4$ and $\mathrm{CD} 8$ single-positive cells, as well as CD4/CD8 double-negative cells $(p<0.05)$ after stimulation by Con A. In contrast, when cells were stimulated with PHA, the reduction of the proliferation was only observed in CD4/CD8 double-negative cells (Figure 1C).

To assess whether an impairment of CD172a+ cells due to cryopreservation could explain the lower frozen PBMC proliferation, cells were stained for CD172a/CD3/CD21/livedead Near-IR. The examination of CD172a+ cells showed that their viability after the overnight resting differed by less than $2 \%$ from that obtained for CD3+ T-cells and the whole PBMC.

\section{Impact of Cryopreservation on IFN- $\gamma$ ELISPOT: Responses to Recall Antigen and Mitogens}

The average number of IFN- $\gamma$-SC in PHA-stimulated fresh PBMC was $1426.6 \pm 274.9$ per $10^{6} \mathrm{PBMC}$ (Figure 2A). After freezing, the average value was $1307.7 \pm 288.5$ (non-significant). Individually, the reduction in the number of IFN- $\gamma$-SC in PHAstimulated never exceeded $-13 \%$ (mean of variance percentage $=$ -8.6 , ranging from $-4.3 \%$ to $-12.8 \%)$. However, when the response to recall antigen was measured, the average frequency of PRRSV-specific IFN- $\boldsymbol{\gamma}$-SC was significantly lower in frozen than in fresh cells $(19.1 \pm 2.4$ versus $33.4 \pm 4.4 ; \mathrm{p}<0.05)$ (Figure 2B). On average, a $41.5 \%$ reduction was observed in frozen cells; individually, from $-21.1 \%$ to $-54.0 \%$ (Supplementary Table 2).

\section{Impact of Cryopreservation on Phenotype and Proliferation of B-Cells}

The proportions of B-cells (gating hierarchy as shown in Figure 3A) before or after freezing were similar $(14.5 \%$ to $24.0 \%$ before freezing versus $13.7 \%$ to $22.7 \%$ after freezing, non-significant) (Figure 3B). The proliferation of B-cells (gating hierarchy as shown in Figure 3A) was impaired in frozen cells stimulated with the recall antigen PRRSV ( $p<$ 0.05), but not in Con A-stimulated cultures. (Figure 3C). Of note, the proportion of $\mathrm{CD} 21^{+}$cells in the 3267 - and ConAstimulated cultures was very low, $<2 \%$ and $<0.6 \%$, respectively. Also, there was an apparent discrepancy between animals.

\section{Impact of Cryopreservation on IgG ELISPOT: Responses to Mitogens}

Regarding the IgG ELISPOT (Figure 4), the response to the mitogenic cocktail (R848 + IL-2) resulted in $453 \pm 131.1$ IgG-SC per $10^{6}$ freshly isolated PBMC, comparable to the average value of frozen cells, $392.2 \pm 120.5$ (non-significant). Variance percentage for the five examined individuals ranged from $-8.5 \%$ to $-19.7 \%$ (mean $=-14.0)$.

\section{DISCUSSION}

The use of frozen PBMC in pig immunology is a common procedure. Most often this is a need arising from the complex logistics required for processing samples collected in a farm located far from the analysis laboratory. However, there is very little information regarding the performance of frozen porcine PBMC compared to freshly isolated ones.

In the present study, the first step was to compare several cryopreservation media. The results of our comparison indicated that the viability after recovery was similar for all three specific freezing media ( $\geq 89 \%$ on average) (Table 1), although cells frozen with PSC Cryopreservation kit showed a trend to perform worse in the IFN- $\gamma$ ELISPOT (Supplementary Table 1). It has been reported that the viability of PBMC below $70-80 \%$ seriously impaired the results of functional tests (19-21). Regarding recovery rates, no obvious impact was observed for any of the cryopreservation procedures (Table 1), obtaining similar results to those described by Liang and collaborators (2019) (22), who found a mean of $73.7 \%$ when comparing five methods. With our results, homemade freezing medium, PSC cryopreservation kit, and CryoStor CS10 fulfilled requirements of viability and recovery. In the following experiments, CryoStor CS10 was used for the sake of convenience.

The additional analyses using a recall antigen or different mitogens showed that the impact of freezing was more evident when the recall responses were examined, as indicated by the reduction of proliferation and the number of spots produced in IFN- $\gamma$ ELISPOT (Figures $\mathbf{1 C}$ and $\mathbf{2 B}$, respectively). Since the viability of $\mathrm{CD}_{172}{ }^{+}$cells, which comprised the majority of antigen presenting cells, did not differ from that of $\mathrm{CD}^{+}$cells or the whole PBMC, the poorer recall response was supposed not caused by extra extent damage of $\mathrm{CD}_{172}{ }^{+}$cells. Such similar studies using human or mice PBMC are still controversial (3-10, 23). Ford et al. (10) reported a decrease in the frequency of antigen-specific IFN- $\gamma$ producing $\mathrm{CD}^{+}{ }^{+} \mathrm{T}$-cells in malaria vaccine studies. According to the authors, the impairment affected mostly short-term IFN $\gamma$-producing effector memory $\mathrm{CD}^{+}{ }^{+} \mathrm{T}$-cells, while the potentially central memory cells seemed to be retained in cryopreserved PBMC. This could be consistent with our observations using porcine cells. Firstly, animals used in the present study were vaccinated against PRRSV one month before sampling, so it would be expectable to have recently developed memory cells (not long-lived yet). Secondly, the effector memory T-cells are thought to be the main 


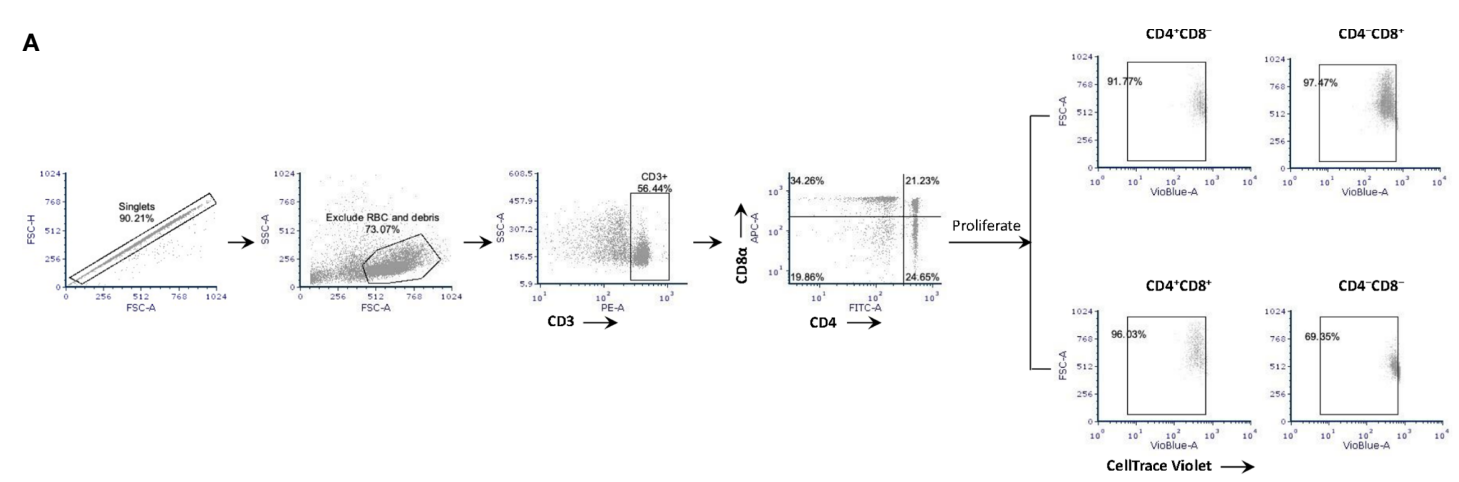

B
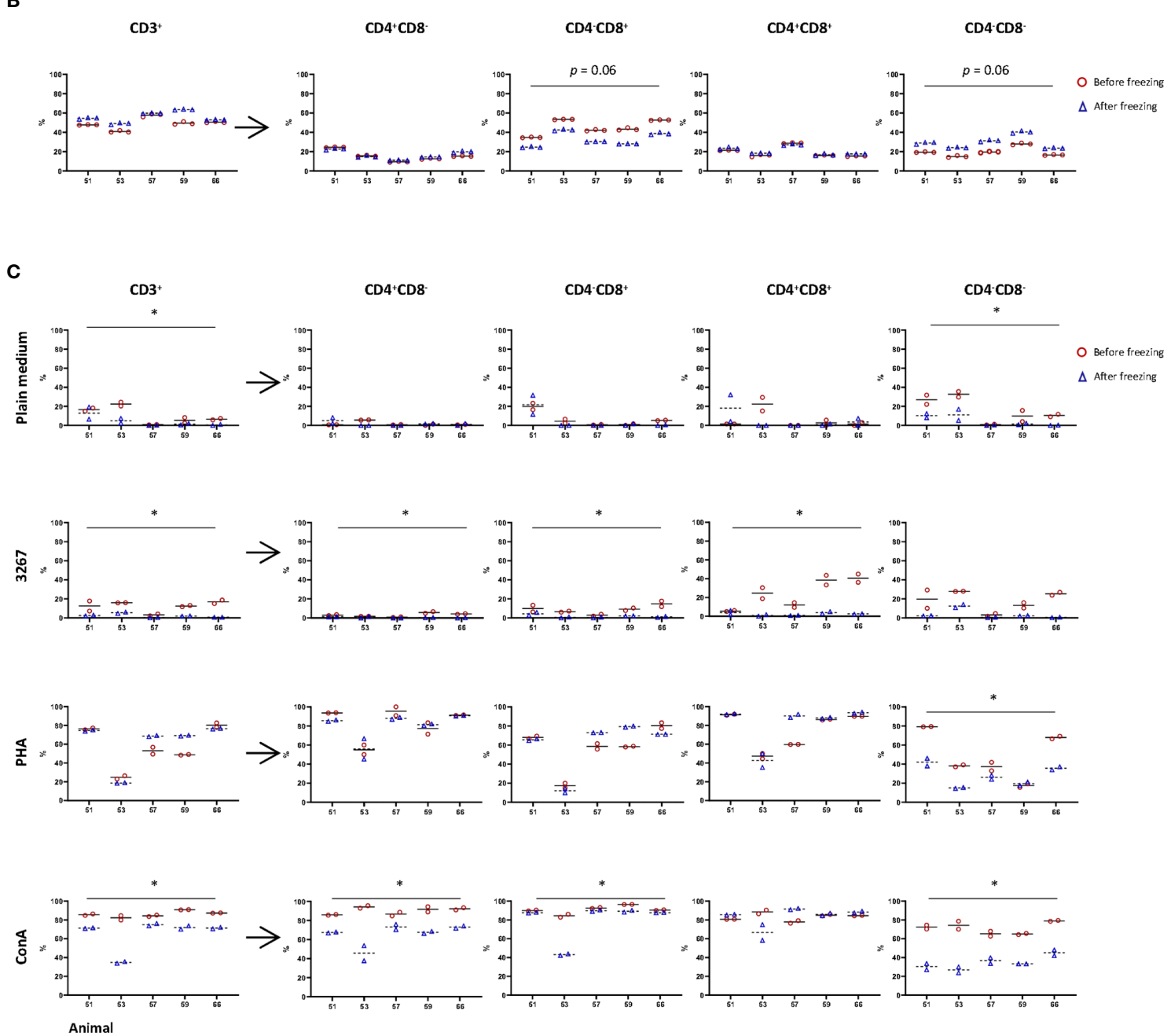

FIGURE 1 | Impact of cryopreservation on phenotype and proliferation of T lymphocytes. (A) Gating hierarchy of T cells. T cells were gated as CD3 ${ }^{+}$cells, then further divided into $\mathrm{CD} 4^{+} \mathrm{CD} 8 \alpha^{-}, \mathrm{CD} 4^{-} \mathrm{CD} 8 \alpha^{+}, \mathrm{CD} 4^{+} \mathrm{CD} 8 \alpha^{+}$, and $\mathrm{CD} 4^{-} \mathrm{CD} 8 \alpha^{-}$. The proliferation of $\mathrm{CD} 3^{+}$cells and the four subsets were assessed by the proportion of CellTrace Violet ${ }^{\text {low }}$ cells within each population; (B) Proportion of $\mathrm{CD}^{+}$cells and different subsets of T cells in fresh (red circles) and frozen (blue triangles) PBMC. Five animals were examined with three replicas per animal, and the means were indicated as solid and dashed lines, respectively; (C) Proliferation of $\mathrm{CD} 3^{+}$cells and subsets $\mathrm{CD} 4^{+} \mathrm{CD} 8 \alpha^{-}, \mathrm{CD} 4^{-} \mathrm{CD} 8 \alpha^{+}, \mathrm{CD} 4^{+} \mathrm{CD} 8 \alpha^{+}$, and $\mathrm{CD} 4^{-} \mathrm{CD} 8 \alpha^{-}$using fresh (red circles) and frozen (blue triangles) PBMC. PBMC were labeled by CellTrace Violet and then stimulated by SM1 (plain medium), PRRSV strain 3267 (3267), Phytohemagglutinin (PHA), or Concanavalin A (Con A) for five days before being stained for CD3/CD4/CD8. Two replicas were shown for both fresh and frozen PBMC with the means indicated as solid and dashed lines, respectively. Statistical significance was calculated by the Wilcoxon's signed ranks test with the average value of each animal, ${ }^{\star} p<0.05$. 


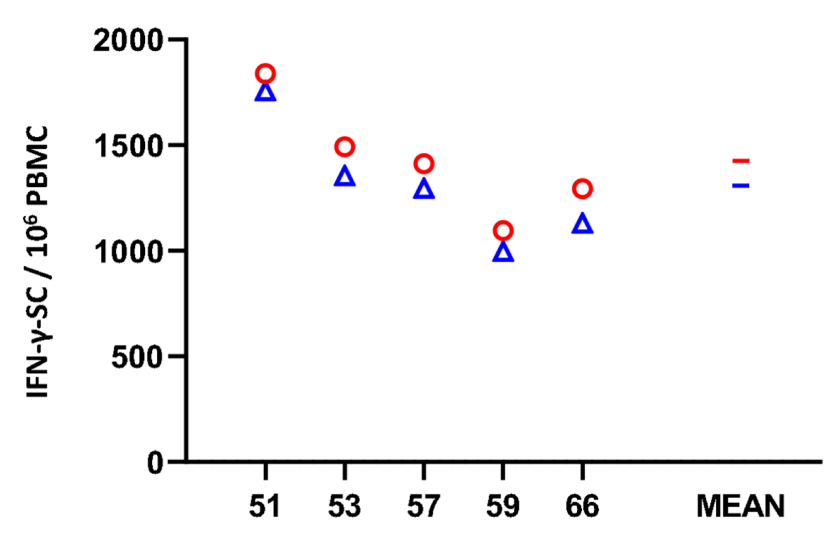

Animal
B

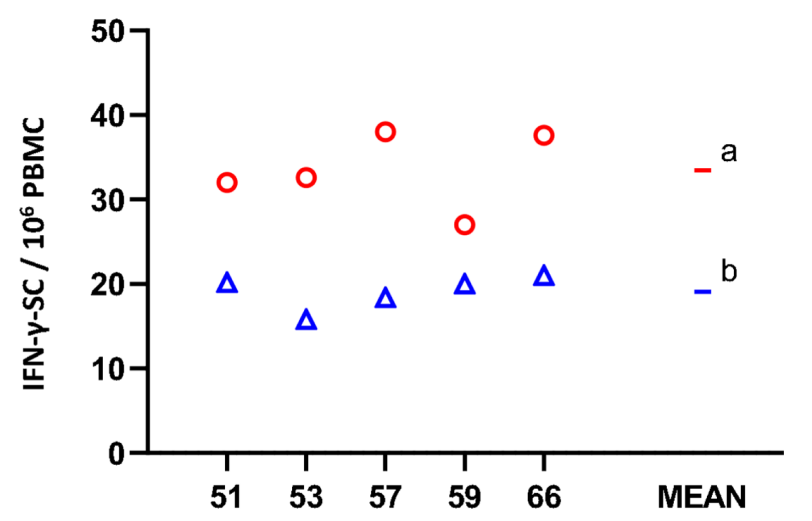

Animal

\section{$\circ$ Before freezing $\Delta$ After freezing}

FIGURE 2 | Impact of cryopreservation on frequencies of IFN- $\gamma$-secreting cells (SC) by means of ELISPOT. (A) PHA-stimulated IFN- $\gamma$-SC by million PBMC. (B) PRRSVspecific IFN- $\gamma$-SC by million PBMC. Results obtained for each pig using fresh PBMC are shown as red circles (mean is indicated by a red line), while results obtained with frozen cells are shown as blue triangles (mean is indicated by a blue line). Statistical significance was calculated by the Mann-Whitney U-test. ${ }^{a, b}$ Superscript letters show significant differences $(p<0.05)$.

source of IFN- $\gamma$ among human $\mathrm{CD} 4^{+}$memory T-cells (revised by 24). Some preliminary evidence was also observed via in vitro restimulation of PBMC from PRRSV-infected pigs (25).

A pre-stimulation step before performing the assay has been suggested to improve the sensitivity of the recall responses in the IFN- $\gamma$ ELISPOT, particularly using frozen cells (26). Interestingly, in a subsequent experiment in which we compared the performance of frozen PBMC from PRRSVvaccinated pigs using pre-stimulation and no-pre-stimulation, we observed a significant increase in the frequency of PRRSVspecific IFN- $\gamma$-SC from two animals, while no improvement was observed from the rest (data not shown). Therefore, as in Smith et al. (26), the improvement observed performing the prestimulation step depended on the individual.

It is worth noting that, in our case, the proliferative response of double positive CD4/CD8 $\alpha$ T-cells to the recall antigen was largely impaired when PBMC were frozen (Figure 1C). Porcine CD4/CD8 double positive cells account for a large proportion of memory cells (27), which have been demonstrated as the primary source of IFN- $\gamma$ when responded to the PRRSV recall stimulation (28). The expression of CD27 further divides them into central (TCM, CD4+/CD8 $\alpha+/ \mathrm{CD} 27+$ ) and effector memory T-cells (TEM, $\mathrm{CD}^{+} / \mathrm{CD} 8 \alpha^{+} / \mathrm{CD} 27^{-}$) (27). As reported by Kick et al. (25), the response of memory cells might be associated with the clearance of PRRSV viremia when pigs were challenged. Upon in vitro re-stimulation, TCM proliferated at a higher level, while TEM are more potent in producing IFN- $\gamma$ and TNF- $\alpha$. A specific impairment of the function of these memory cells after freezing may undermine their role in response to different antigens, at least to PRRSV. But other studies on human PBMC indicated that freezing did not have a substantial effect on the recall responses (4-6). Further confirmation would require a specific analysis of the naïve, TCM and TEM compartments using animals at different times of immunisation (short- and longterm after antigen exposure).

When using mitogens for T-cells or polyclonal activation of B-cells, the picture was different (Figures 2A, 4, respectively; Supplementary Table 2). The impact of freezing seemed to be of minor importance, if any, for polyclonally activated PBMC used in the IFN- $\gamma$ of IgG ELISPOT. Li et al. (12) suggested that freezing of porcine PBMC could even result in a slight increase in the cytokine production upon PMA stimulation.

In our case, when PHA was used, the proliferation of T-cells was slightly affected. But the individual variation was noticeable, and in some cases, cells that were frozen showed even a higher proliferation (Figure 1C). In contrast, Koch et al. (11) reported a decreased proliferation, as measured by $3 \mathrm{H}$-thymidine incorporation, but, in Koch's study, PBMC were not rested after thawing. In others papers it has been shown that resting PBMC after thawing improved the proportion of T-cells, particularly CD4 (15).

In striking contrast, proliferation after stimulation with Con A was significantly impaired in cells that were frozen (Figure 1C). The precise mechanisms by which PHA and Con A induce T-cell proliferation are poorly understood. Besides being lectins and acting by crosslinking, activation of T-cells by Con A and PHA might happen via distinct molecular machinery. For example, CD28 was assumed to be a co-stimulatory signal 
A

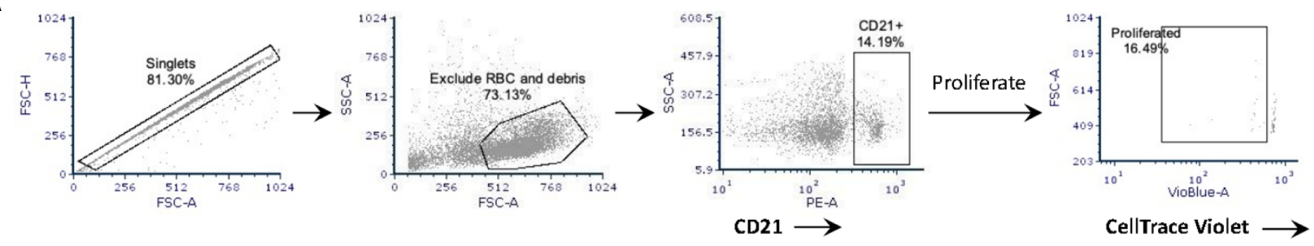

$\mathrm{CD}^{2} 1^{+}$

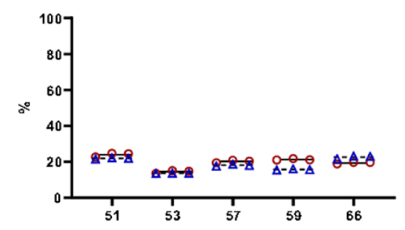

O Before freezing

$\Delta$ After freezing

C

Medium only

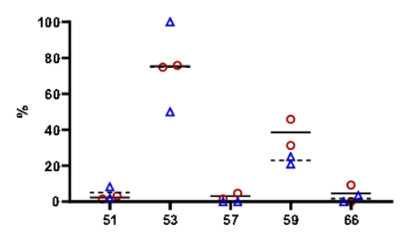

Animal
3267

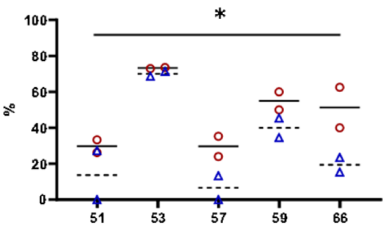

ConA

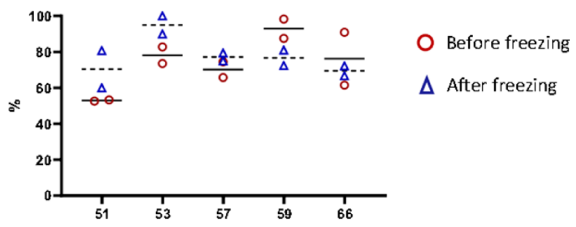

FIGURE 3 | Impact of cryopreservation on phenotype and proliferation of B lymphocytes. (A) Gating hierarchy of B cells. B cells were gated as CD21 $1^{+}$cells. The proliferation was assessed by the proportion of CD21+ cells with CellTrace Violet ${ }^{\text {low; }}$ (B) Comparison of the proportion of CD21 $1^{+}$cells in fresh (red circles) and frozen (blue triangles) PBMC. Five animals in three replicas were shown. The means were indicated with solid (fresh PBMC) and dashed lines (frozen PBMC), respectively; (C) Proliferation of $\mathrm{CD} 21^{+}$cells. PBMC (labeled with CellTrace Violet) were stained for CD21 after five days of stimulation by SM1 (plain medium), PRRSV strain 3267 (3267), or Concanavalin A (Con A). Two replicas were shown for both fresh (red circles) and frozen (blue triangles) PBMC with the means indicated as solid and dashed lines, respectively. Statistical significance was calculated by the Wilcoxon's signed ranks test with the average value of each animal, ${ }^{*} p<0.05$.

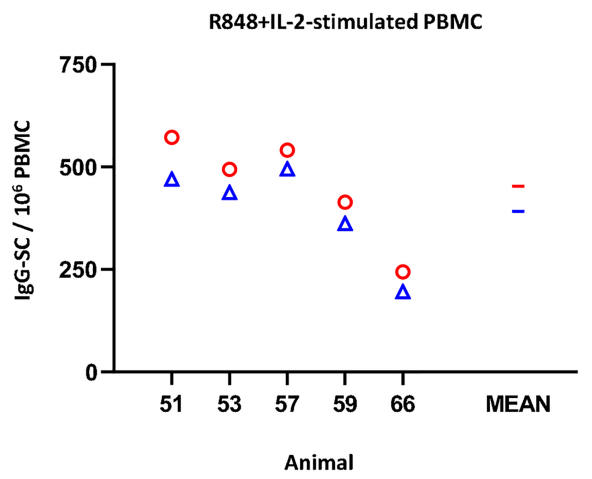

FIGURE 4 | Impact of cryopreservation on frequencies of IgG-secreting cells (SC) by means of ELISPOT. R848+IL-2-stimulated IgG-SC by million PBMC. Results obtained for each pig using fresh PBMC are shown as red circles (mean is indicated by a red line), while results obtained with frozen cells are shown as blue triangles (mean is indicated by a blue line). 
during Con A stimulation (29), which has not been proved for PHA. The precise reason by which freezing affected cultures activated with one or the other lectin cannot be ascertained in the present study.

The last effect related to the freezing was a decrease in the proportion of $\mathrm{CD} 21^{+}$cells. Reimann et al. (3) determined that freezing resulted in a decrease of the proportion of $\mathrm{CD}_{19}{ }^{+}$cells in PBMC from HIV patients. The causes of such loss were not resolved at that moment and are also unable to be determined through our results. But, in any case, the loss of $\mathrm{CD} 21^{+}$cells did not significantly affect the IgG ELISPOT.

To conclude, our results suggest that frozen porcine PBMC are mostly suitable for immunophenotyping and functional testing as long as mitogens are used. For recall antigen stimulation, freezing had a significant impact on the magnitude of the response, although responding animals could be identified. Nevertheless, same PBMC condition (fresh or frozen) should be used within a given study/trial to ensure comparability of the results. Given that freezing is a common treatment when working with porcine PBMC, it would be advisable to further characterize the response of naïve and memory cells at different times of the immune response.

\section{DATA AVAILABILITY STATEMENT}

The raw data supporting the conclusions of this article will be made available by the authors, without undue reservation.

\section{ETHICS STATEMENT}

The animal study was reviewed and approved by Comissio d'ètica en experimentació animal i humana (2501CEEA-UAB).

\section{REFERENCES}

1. Elliott GD, Wang S, Fuller BJ. Cryoprotectants: A Review of the Actions and Applications of Cryoprotective Solutes That Modulate Cell Recovery From Ultra-Low Temperatures. Cryobiology (2017) 76:74-91. doi: 10.1016/ j.cryobiol.2017.04.004

2. Prince HE, Lee CD. Cryopreservation and Short-Term Storage of Human Lymphocytes for Surface Marker Analysis. Comparison of Three Methods. J Immunol Methods (1986) 93(1):15-8. doi: 10.1016/0022-1759(86)90427-8

3. Reimann KA, Chernoff M, Wilkening CL, Nickerson CE, Landay AL. Preservation of Lymphocyte Immunophenotype and Proliferative Responses in Cryopreserved Peripheral Blood Mononuclear Cells From Human Immunodeficiency Virus Type 1-Infected Donors: Implications for Multicenter Clinical Trials. The ACTG Immunology Advanced Technology Laboratories. Clin Diagn Lab Immunol (2000) 7(3):352-9. doi: 10.1128/CDLI.7.3.352-359.2000

4. Kreher CR, Dittrich MT, Guerkov R, Boehm BO, Tary-Lehmann M. CD4+ and CD8+ Cells in Cryopreserved Human PBMC Maintain Full Functionality in Cytokine ELISPOT Assays. J Immunol Methods (2003) 278(1-2):79-93. doi: 10.1016/s0022-1759(03)00226-6

5. Bull M, Lee D, Stucky J, Chiu YL, Rubin A, Horton H, et al. Defining Blood Processing Parameters for Optimal Detection of Cryopreserved AntigenSpecific Responses for HIV Vaccine Trials. J Immunol Methods (2007) 322(12):57-69. doi: 10.1016/j.jim.2007.02.003

\section{AUTHOR CONTRIBUTIONS}

YL contributed to the design and the execution of part of the experiments, the interpretation of the data, and the writing of the manuscript. EM contributed to the design of the experiments, the interpretation of the data, and the writing of the manuscript. ID contributed to the design and the execution of part of the experiments, the interpretation of the data, and the writing of the manuscript. All authors contributed to the article and approved the submitted version.

\section{FUNDING}

This work was partially supported by the National Institute of Research and Agricultural and Food Technology (INIA, reference E-RTA2015-0003-C02-01) and by funds of the Laboratori Veterinari de Diagnosi de Malalties Animals of the Universitat Autònoma de Barcelona (UAB).

\section{ACKNOWLEDGMENTS}

We would like to thank all researchers and technicians from UAB and IRTA involved in E-RTA2015-0003-C02-01. We also thank Gerard E Martín-Valls (UAB, Spain) for help in the collection of blood. CERCA Programme from the Generalitat de Catalunya is also acknowledged.

\section{SUPPLEMENTARY MATERIAL}

The Supplementary Material for this article can be found online at: https://www.frontiersin.org/articles/10.3389/fimmu.2021.765667/ full\#supplementary-material

6. Mallone R, Mannering SI, Brooks-Worrell BM, Durinovic-Belló I, Cilio CM, Wong FS, et al. T-Cell Workshop Committee, Immunology of Diabetes Society. Isolation and Preservation of Peripheral Blood Mononuclear Cells for Analysis of Islet Antigen-Reactive T Cell Responses: Position Statement of the T-Cell Workshop Committee of the Immunology of Diabetes Society. Clin Exp Immunol (2011) 163 (1):33-49. doi: 10.1111/j.1365-2249.2010.04272.x

7. Costantini A, Mancini S, Giuliodoro S, Butini L, Regnery CM, Silvestri G, et al. Effects of Cryopreservation on Lymphocyte Immunophenotype and Function. J Immunol Methods (2003) 278(1-2):145-55. doi: 10.1016/s00221759(03)00202-3

8. Tompa A, Nilsson-Bowers A, Faresjö M. Subsets of CD4+, CD8+, and CD25hi Lymphocytes Are in General Not Influenced by Isolation and Long-Term Cryopreservation. J Immunol (2018) 201(6):1799-809. doi: 10.4049/jimmunol.1701409

9. Baust JM, Corwin W, Snyder KK, Van Buskirk R, Baust JG. Cryopreservation: Evolution of Molecular Based Strategies. Adv Exp Med Biol (2016) 951:13-29. doi: 10.1007/978-3-319-45457-3_2

10. Ford T, Wenden C, Mbekeani A, Dally L, Cox JH, Morin M, et al. Cryopreservation-Related Loss of Antigen-Specific Ifn $\gamma$ Producing CD4+ TCells can Skew Immunogenicity Data in Vaccine Trials: Lessons From a Malaria Vaccine Trial Substudy. Vaccine (2017) 35(15):1898-906. doi: $10.1016 /$ j.vaccine.2017.02.038 
11. Koch E, Larak M, Ellendorff F. Comparative Studies on In Vitro Reactivity of Fresh and Cryopreserved Pig Lymphocytes. Cryobiology (1991) 28(5):405-12. doi: 10.1016/0011-2240(91)90048-s

12. Li X, Zhong Z, Liang S, Wang X, Zhong F. Effect of Cryopreservation on IL-4, IFNgamma and IL-6 Production of Porcine Peripheral Blood Lymphocytes. Cryobiology (2009) 59(3):322-6. doi: 10.1016/j.cryobiol.2009.09.004

13. Gimeno M, Darwich L, Diaz I, de la Torre E, Pujols J, Martín M, et al. Cytokine Profiles and Phenotype Regulation of Antigen Presenting Cells by Genotype-I Porcine Reproductive and Respiratory Syndrome Virus Isolates. Vet Res (2011) 42(1):9. doi: 10.1186/1297-9716-42-9

14. Kutscher S, Dembek CJ, Deckert S, Russo C, Körber N, Bogner JR, et al. Overnight Resting of PBMC Changes Functional Signatures of Antigen Specific T- Cell Responses: Impact for Immune Monitoring Within Clinical Trials. PloS One (2013) 8(10):e76215. doi: 10.1371/journal.pone.0076215

15. Lemieux J, Jobin C, Simard C, Néron S. A Global Look Into Human T Cell Subsets Before and After Cryopreservation Using Multiparametric Flow Cytometry and Two-Dimensional Visualization Analysis. J Immunol Methods (2016) 434:73-82. doi: 10.1016/j.jim.2016.04.010

16. Díaz I, Pujols J, Cano E, Cortey M, Navarro N, Vidal A, et al. Immune Response Does Not Prevent Homologous Porcine Epidemic Diarrhoea Virus Reinfection Five Months After the Initial Challenge. Transbound Emerg Dis (2021) 00:1-13. doi: 10.1111/tbed.14055

17. Jahnmatz M, Kesa G, Netterlid E, Buisman AM, Thorstensson R, Ahlborg N. Optimization of a Human IgG B-Cell ELISpot Assay for the Analysis of Vaccine-Induced B-Cell Responses. J Immunol Methods (2013) 391(1-2):509. doi: 10.1016/j.jim.2013.02.009

18. Saalmüller A, Pauly T, Höhlich BJ, Pfaff E. Characterization of Porcine T Lymphocytes and Their Immune Response Against Viral Antigens. J Biotechnol (1999) 73(2-3):223-33. doi: 10.1016/s0168-1656(99)00140-6

19. Weinberg A, Zhang L, Brown D, Erice A, Polsky B, Hirsch MS, et al. Viability and Functional Activity of Cryopreserved Mononuclear Cells. Clin Diagn Lab Immunol (2000) 7(4):714-6. doi: 10.1128/CDLI.7.4.714-716.2000

20. Maecker HT, Moon J, Bhatia S, Ghanekar SA, Maino VC, Payne JK, et al. Impact of Cryopreservation on Tetramer, Cytokine Flow Cytometry, and ELISPOT. BMC Immunol (2005) 6:17. doi: 10.1186/1471-2172-6-17

21. Consuegra I, Rodríguez-Aierbe C, Santiuste I, Bosch A, Martínez-Marín R, Fortuto MA, et al. Isolation Methods of Peripheral Blood Mononuclear Cells in Spanish Biobanks: An Overview. Biopreserv Biobank (2017) 15(4):305-9. doi: 10.1089/bio.2016.0105

22. Liang $\mathrm{X}, \mathrm{Hu} \mathrm{X}, \mathrm{Hu} \mathrm{Y}$, Zeng W, Zeng G, Ren Y, et al. Recovery and Functionality of Cryopreserved Peripheral Blood Mononuclear Cells Using Five Different Xeno-Free Cryoprotective Solutions. Cryobiology (2019) 86:2532. doi: $10.1016 /$ j.cryobiol.2019.01.004
23. Owen RE, Sinclair E, Emu B, Heitman JW, Hirschkorn DF, Epling CL, et al. Loss of T Cell Responses Following Long-Term Cryopreservation. J Immunol Methods (2007) 326(1-2):93-115. doi: 10.1016/j.jim.2007.07.012

24. Farber DL, Yudanin NA, Restifo NP. Human Memory T Cells: Generation, Compartmentalization, and Homeostasis. Nat Rev (2014) 14(1):24-35. doi: $10.1038 /$ nri3567

25. Kick AR, Amaral AF, Cortes LM, Fogle JE, Crisci E, Almond GW, et al. The T-Cell Response to Type 2 Porcine Reproductive and Respiratory Syndrome Virus (PRRSV). Viruses (2019) 11(9):796. doi: 10.3390/ v11090796

26. Smith SG, Joosten SA, Verscheure V, Pathan AA, McShane H, Ottenhoff TH, et al. Identification of Major Factors Influencing ELISpot-Based Monitoring of Cellular Responses to Antigens From Mycobacterium Tuberculosis. PloS One (2009) 4(11):e7972. doi: 10.1371/journal.pone.0007972

27. Reutner K, Leitner J, Müllebner A, Ladinig A, Essler SE, Duvigneau JC, et al. CD27 Expression Discriminates Porcine T Helper Cells With Functionally Distinct Properties. Vet Res (2013) 44(1):18. doi: 10.1186/ 1297-9716-44-18

28. Meier WA, Galeota J, Osorio FA, Husmann RJ, Schnitzlein WM, Zuckermann FA. Gradual Development of the Interferon-Gamma Response of Swine to Porcine Reproductive and Respiratory Syndrome Virus Infection or Vaccination. Virology (2003) 309(1):18-31. doi: 10.1016/s0042-6822(03)00009-6

29. Shahinian A, Pfeffer K, Lee KP, Kündig TM, Kishihara K, Wakeham A, et al. Differential T Cell Costimulatory Requirements in CD28-Deficient Mice. Science (1993) 261(5121):609-12. doi: 10.1126/science.7688139

Conflict of Interest: The authors declare that the research was conducted in the absence of any commercial or financial relationships that could be construed as a potential conflict of interest.

Publisher's Note: All claims expressed in this article are solely those of the authors and do not necessarily represent those of their affiliated organizations, or those of the publisher, the editors and the reviewers. Any product that may be evaluated in this article, or claim that may be made by its manufacturer, is not guaranteed or endorsed by the publisher.

Copyright $\odot 2021 \mathrm{Li}$, Mateu and Díaz. This is an open-access article distributed under the terms of the Creative Commons Attribution License (CC BY). The use, distribution or reproduction in other forums is permitted, provided the original author(s) and the copyright owner(s) are credited and that the original publication in this journal is cited, in accordance with accepted academic practice. No use, distribution or reproduction is permitted which does not comply with these terms. 